\title{
Pheromone trapping system for Rhynchophorus ferrugineus in Saudi Arabia: Optimization of trap contents and placement
}

\author{
Mahmoud Mohamed Abdel-Azim, Saleh Abdullah Aldosari, Rashid Mumtaz, Polana S.P.V. Vidyasagar, \\ Paraj Shukla* \\ Department of Plant Protection, College of Food and Agricultural Sciences, P.O. Box 2460, King Saud University, Riyadh 11451, Saudi \\ Arabia
}

\section{A B S T R A C T}

\begin{abstract}
The red palm weevil, Rhynchophorus ferrugineus Olivier is a major pest of date palm. The pheromone-based mass trapping of weevils has traditionally been an important component of integrated pest management program for this pest. In order to maximize the trap catches, six field experiments were conducted in the present study including evaluation of stump trap, lures, lure synergist ethyl acetate, kairomones, food baits and yeast. The stump trap lured more weevils than the tree trap. The three tested pheromone lures were similar in attraction but with ethyl acetate, Ferrolure $+{ }^{\mathrm{TM}}$ lured more weevils than RHYFER ${ }^{\mathrm{TM}}$. Amongst the tested kairomones, acetic acid and ethyl acetate alone and together emerged as strong synergists to lure. The date fruits, date palm stem pieces and sugarcane pieces attracted similar number of weevils but in presence of ethyl acetate, date fruits attracted significantly more adults. Date fruits attracted more weevils with yeast than alone but overall, date fruits, yeast and ethyl acetate together recorded the highest trap catches. The differences in attraction of weevils due to various treatments have been analyzed and results are discussed.
\end{abstract}

Keywords: Red palm weevil; Pheromone trap; Date palm; Kairomone; Stump trap; Food bait

\section{INTRODUCTION}

The red palm weevil (RPW), Rhynchophorus ferrugineus Oliv. (Coleoptera: Dryophthoridae) has emerged as the most destructive global pest of palm trees attacking more than 35 species from 23 palm genera (Giblin-Davis et al., 2013; Al-Dosary et al., 2016). Although, native of South-East Asia and Melanesia, the RPW has spread to over 30 countries in Asia, Europe and Oceania in the last three decades. The characteristics such as adaptability to temperature and different host plants, immune-priming against infections, and genetic diversity of the population have been credited for its wide regional inhabitation (Peng and Hou, 2017). The Food and Agriculture Organization, United Nations has designated RPW a category-1 pest of date palm (Phoenix dactylifera) in the Middle-East region (Faleiro et al., 2011). According to an estimate, the annual losses at 1 and 5\% RPW infestation levels have been reported to the tune of US\$1.74 to 8.69 million, respectively, in the middle-eastern region alone (El-Sabea et al., 2009). The death losses of the trees are compounded by the costs associated with their removal and disposal.

In case of moderate to severe infestation, all life stages of RPW from the overlapping generations can be found inside the palm trunks (Rajamanickam et al., 1995; Avand Faghih, 1996). The extensive tunneling inside the trunk due to feeding by voracious grubs eventually leads to demise of the tree (Ferry and Gomez, 2002). Due to hidden nature of the pest, chemical methods of control which involve repeated applications of large quantities of insecticides for both prevention and curing the infestations, yield limited results (Faleiro, 2006; Kaakeh, 2006; Dembilio et al., 2010; Llacer et al., 2010). Additionally, nearly absent external symptoms in early stages of RPW infestation cause delay in the implementation of curative procedures. This makes it essential for RPW integrated pest management programs to include constant monitoring of pest population by

\footnotetext{
${ }^{*}$ Corresponding author:

Paraj Shukla, Department of Plant Protection, P.O. Box No. 2460, College of Food and Agricultural Sciences, King Saud University, Riyadh 11451, Kingdom of Saudi Arabia, Tel: +966 46 93378. Email: parajshukla@gmail.com
} 
trapping methods. During or after devouring the host, adults emerge and fly out in search of food resources and mates and cause re-infestations or newly infest the healthy palms (Nirula, 1956; Estaban-Durán et al., 1998). These outbound adults are targeted by semiochemical-based trapping methods which have been used as the mainstay of IPM programs in many countries to monitor and mass-trap the RPW populations in the field (Oehlschlager et al., 1993; Abraham et al., 1998; Rajapakse et al., 1998; Vidyasagar and Subaharan, 2000; Vidyasagar et al., 2000b; Oehlschlager et al., 2002; Soroker et al., 2005; Abbas et al., 2006; El-Sayed et al., 2006). A major advantage of RPW pheromone trapping is that it attracts nearly twice the number of females than males and thereby further helping to reduce progenies (Oehlschlager, 1998; Vidyasagar et al., 2000b; Abraham et al., 2001; Faleiro et al., 2002; Faleiro, 2005; Jayanth et al., 2007; Vacas et al., 2013, 2014).

Despite the practices of RPW pheromone trapping being done since two decades, the holistic optimization of protocols with regards to the trap density, design, placement and various internal components including lure, co-attractant, food bait, insecticide, etc., are contemporary research topics as evident from recent studies (Vidyasagar et al., 2016; El-Shafie and Faleiro, 2017; Vacas et al., 2017). The traditional pheromone trapping systems for RPW in Saudi Arabia are based on broadly four components: bucket trap, aggregation pheromone, kairomone and insecticide. The bucket traps are in widespread use throughout the country. They are hung on palm trees and usually not placed on or buried in the ground (Hallett et al., 1993b; Rajapakse et al., 1998; Abraham et al., 2000; Vidyasagar et al., 2000b; Faleiro, 2005, 2006). On the other hand, stump trap (Massoud et al., 2012; Hoddle et al., 2013) is gaining popularity where bucket trap is placed on the top of stump, which are essentially log pieces of date palm deadwood. In the present study, bucket trap placement on the tree (tree trap) was compared with that on the stump (stump trap). The trap color have already been studied extensively (Abuagla and Al-Deeb, 2012; Al-Saoud, 2013; Abdel-Azim et al., 2014; Avalos and Soto, 2015). The role of semiochemicals in management of a cryptic pest like RPW has been elaborated before (Soroker et al., 2015). The male produced aggregation pheromone of RPW, which attracts both the sexes, was reported to be a mixture of two compounds, 4-methyl-5-nonanol (major component, ferrugineol) and 4-methyl-5-nonanone (minor component, ferrugineone) (Hallet et al., 1993a) and use of both components in the lure (9:1 ratio) increased catches by 75 per cent (Abozuhairah et al., 1996). In Saudi Arabia, all the three readily available commercial pheromone lures, i.e. Ferrolure+TM (ChemTica), RHYFER ${ }^{\mathrm{TM}}$ (Alpha Scents) and RHYNCAPTM (Green Universe) are available as 9:1 mixture of the ferrugineol and ferrugineone. Hallet et al. (1999) reported $3 \mathrm{mg} /$ day as effective release rate of ferrugineol but recently 4-5 $\mathrm{mg}$ /day was reported for maximum trap catches (Vacas et al., 2017). However, the emission rates of commercial pheromones in spite of same composition may differ due to the difference in the pheromone holding matrices used in the packaging. Therefore, in the present study, the three lures with different holding matrices were evaluated for their RPW attraction efficacy.

The third component of the trap, kairomone, is a contemporary subject of extensive research globally. The kairomones synergize the RPW attraction by lure to augment the trap catches (Hallett et al., 1993a). With the trap perspective, the kairomone component can be segregated into two parts: (a) semiochemical hung as coattractant in the trap along with lure (Oehlschlager, 1998; El-Sebay, 2003; Abdallah and Al-Khatri, 2005; Al-Shagag et al., 2008; Al-Saoud, 2013; Vacas et al., 2013) and (b) volatiles released from the food bait directly and/or after fermentation (Oehlschlager et al., 1993; Anonymous, 1998; Faleiro and Chellapan, 1999; Faleiro et al., 1999; Hallett et al., 1999; Murphy and Briscoe, 1999; Nair et al., 2000; Muthiah et al., 2005; Soroker et al., 2005; Oehlschlager, 2006; Rochat, 2006; Sivapragasam et al., 2010; Hoddle and Hoddle, 2011; Azmi et al., 2014). It is pertinent to state here that the kairomones (co-attractants) and kairomone-producing food baits poorly attract the weevils by themselves, but their presence in the trap substantially synergizes the attraction by pheromone lure (Vacas et al., 2013). In Saudi Arabia, the use of co-attractant is limited to ethyl acetate. Notably, like ethyl acetate, ethanol and acetic acid have also been discovered in the fermenting food volatile mixtures (Rochat et al., 2000). In the present study, co-attractants, ethyl acetate, ethanol and acetic acid were evaluated for their lure synergistic activity.

If the trap is equipped with pheromone lure but not baited with food, weevil catches drop significantly. Several studies have highlighted the importance of food baits to sustain RPW pheromone trap catches (Faleiro and Chellapan, 1999; Hallett et al., 1999; Nair et al., 2000; Faleiro and Satarkar, 2003; Oehlschlager, 2007). The food baits used in Saudi Arabia are predominantly date fruits (fodder grade) with some growers also using date palm and sugarcane stem pieces. Therefore in the present study, the three food baits and their respective combination with ethyl acetate were evaluated for maximizing the trap catches. Regarding the food bait, the food components need to be wet and in a state of gradual degradation or fermentation for sustaining high RPW trap catches (Hallett et al., 1999; Oehlschlager, 2016). The wet food ferments faster and releases additional volatiles which are considered essential for short-range orientation of weevils towards traps (Gunawardena and 
Gunatilake, 1993; Avalos and Soto, 2015). If this is the case, expediting and/or facilitating the fermentation of food should increase the release rate and variety of food volatiles from the trap. Therefore, in the present study, fast fermenting food bait of fodder grade date fruits with yeast was evaluated to augment and sustain the RPW trap catches. Moreover, ethyl acetate is a known fermenting food volatile and therefore the food-baited traps with a dedicated ethyl acetate release source were also evaluated with and without yeast. No evaluation with regards to fourth trap component, insecticide, was undertaken in the present study as efforts are underway to make the trap organic and avoid the insecticide use. The results would strengthen the mass-trapping strategies by doing the suitable interventions in the current practices.

\section{MATERIALS AND METHODS}

\section{Study location}

Three date palm orchards at Al Kharj Governorate ( $24^{\circ} 8^{\prime} 54^{\prime \prime} \mathrm{N}$ latitude, $47^{\circ} 18^{\prime} 18^{\prime \prime}$ E longitude), $77 \mathrm{~km}$ south of Riyadh, Saudi Arabia, were chosen for this study. Based on the experimental design, the orchards with trees of similar age (10 to 15 years) and having moderate to severe infestation were selected for experiment. The routine trapping was halted for two weeks before initiating the experiments to offset the change in adult population due to emergence of adults thereby ensuring that the weekwise trap catches were nearly uniform before starting the field experiments.

\section{Standard Saudi trap}

Six liters, black-colored (Abdel-Azim et al., 2015) plastic buckets were fabricated into traps by making four $3 \times 6 \mathrm{~cm}$ windows equidistant from each other and about $2 \mathrm{~cm}$ below the upper rim. To facilitate the climbing by weevils, a darkcolored rough jute cloth was wrapped around the bucket without obstructing the windows. The pheromone lure dispenser was hung on the inner side of the bucket lid by a wire. The Ferrolure ${ }^{+{ }^{T M}}$ sachets (Chem Tica International, Costa Rica) loaded with $700 \mathrm{mg}$ of aggregation pheromone components, 4-methyl-5-nonanol and 4-methyl-5nonanone in 9:1 ratio at $98 \%$ purity of enantiomeric mixture, were used as the standard pheromone lure. The bucket was filled with $\sim 2 \mathrm{~L}$ of tap water and $2 \mathrm{~g}$ insecticide (Carbaryl, 10 \% WP; Kafr Elzayat Pesticides and Chemicals Co., Egypt) was added to it. About $200 \mathrm{~g}$ of fodder grade date fruits were used as the standard food bait along with 3 g of yeast (Saccharomyces cerevisiae) powder (Saf-instant S.I.Lesaffre - 59703 Marcq - France). For dispensing ethyl acetate, $12 \mathrm{ml}(19 \times 65 \mathrm{~mm})$ amber glass vial (Agilent Technologies, USA) with a polyethylene lid having two $1 \mathrm{~mm}$ holes was filled with $10 \mathrm{ml}$ ethyl acetate (> 99\% purity; Fisher Scientific UK) and suspended along side pheromone lure. As per the evaluated component/s in the experiments, the standard pheromone lure and food bait were replaced with other options, while yeast and ethyl acetate were removed. Shaded areas in the orchard were chosen for the trap placement to maintain a uniform and sustained release of volatiles from the trap while ensuring longer service life of pheromone lure under arid environment of Saudi Arabia. The traps were suspended on the palm trunks at a height of about $1.2 \mathrm{~m}$ by wire.

\section{Field experiment setup}

Total six sets of field experiments were conducted involving evaluation of trap placement and various trap contents including pheromone lures, kairomones, food baits and food fermenting agent. The traps were placed in random block design (RBD) while maintaining $\sim 50 \mathrm{~m}$ spacing between treatments and $\sim 200 \mathrm{~m}$ between replications. Each experiment was conducted within single orchard to obviate differences due to age of palm trees, level of RPW infestation and general agronomic practices. In each of the six experiments, the traps were examined for removing and recording dead or alive male and female adult catches, and replenishing the wet contents to their original level for the sake of uniformity. Since the experiments continued between 4 to 12 weeks, the pheromone lures, irrespective of the quantity of their contents, were also replaced in all traps after six weeks. In addition, to eliminate spot effect due to aggregation of weevils (Faleiro et al., 2002), the traps were shuffled within replications. Generally, the efficiency of pheromone trapping was correlated to the number of weevils captured in each trap during the experimental period.

\section{Stump trap}

In the first experiment of the present study, stump traps were evaluated by installing bucket traps on the top of the date palm stump ( $75 \mathrm{~cm}$ height). Stumps for holding bucket traps were made from dry palm stems obtained from the neglected or discarded palms. The tree trunks were cut longitudinally in $\sim 75 \mathrm{~cm}$ pieces by using a mechanical saw. Then a central hole was made manually on top of each stump using a sharp shovel to fit the standard Saudi bucket trap. The depth of the hole was made till the windows in the bucket trap. The stumps were then thoroughly treated with pesticide to avoid infestation from deviating weevils. In this experiment, the following treatments with standard Saudi trap were compared in the field: (1) Hanged on the trunk of a palm tree (about 1.2 above the ground level), hereafter referred as 'Tree Trap' and (2) Placed in the groove on the top of a date palm stump (about $25-35 \mathrm{~cm}$ radius and about $70 \mathrm{~cm}$ height), hereafter referred as 'Stump Trap'. The two treatments were applied with 13 replications each (26 traps) for 12 weeks. The trap catches were recorded every second week. 


\section{Pheromone lure}

In the second field experiment, 18 standard Saudi trap described before were installed (3 treatments x 6 replications). Apart from standard lure used in the present study, two more commercially available RPW aggregation pheromone lures were evaluated for field efficacy. The Ferrolure ${ }^{\mathbf{T M}}$ (ChemTica International Co., Costa Rica) is available in a porous and inert sachet $(5 \times 6 \mathrm{~cm})$ loaded with $700 \mathrm{mg}$ of pheromone mixture comprising 4-methyl-5nonanol (9 parts) + 4-methyl-5-nonanone (1 part) - purity 99.9\%. The other two lures, RHYFER ${ }^{\mathrm{TM}}$ (Alpha Scents Inc., USA) and RHYNCAPTM (Green Universe Agriculture S.L., Spain) were same component-wise, but used paper material saturated with pheromone mixture and packed in permeable plastic bag as dispenser. While Alpha Scents lure used an absorbent matrix which is a round and thick paper disk $(3.8 \mathrm{~cm}$ diameter $\times 0.2 \mathrm{~cm}$ thickness) loaded with $700 \mathrm{mg}$ of pheromone mixture and packaged in inert permeable plastic bag, the RHYNCAPTM contained a thick but bigger and rectangular paper $(6.8 \times 6 \times 0.2 \mathrm{~cm})$ enclosed in impermeable aluminum bag $(7.5 \times 6.2 \mathrm{~cm})$ with a permeable transparent plastic square $(4.2 \mathrm{~cm}$ side) window on one side. Experiment was held for 10 weeks and trap catches were recorded every alternate week.

\section{Lure and ethyl acetate}

Based on the results from pheromone lure evaluation experiment, the two better performing lures, Ferrolure + TM and RHYFER ${ }^{\text {TM }}$ were tested with and without ethyl acetate in the third experiment for the trap catches. The standard Saudi trap was used without yeast, and except lure and ethyl acetate, all other standard components were retained. The experiment was replicated nine times with four treatments (36 traps). A weekly record of the number of weevils trapped was maintained for the study period of four weeks.

\section{Kairomone}

The most common kairomone, ethyl acetate was evaluated against other potential kairomones including ethanol (Merck Millipore), and acetic acid (Merck Millipore) in the fourth experiment. Kairomones were also dispensed like ethyl acetate and suspended along side pheromone lure in the standard Saudi trap. In total, five treatments were tested in standard Saudi trap: (i) ethyl acetate; (ii) acetic acid; (iii) ethyl acetate and acetic acid (in separate vial dispensers); (iv) ethanol and (v) Control (water only; without kairomone). All tested kairomones were refilled in the vials when the quantity reached $5 \mathrm{ml}$ mark. The treatments were replicated ten times and the trap catches were sexed and counted on a weekly basis for a total of five weeks.

\section{Food bait}

In the fifth experiment, the standard Saudi trap was used to evaluate three types of food baits, viz. date palm stem pieces, date fruits and sugarcane pieces, with and without ethyl acetate in a total of six treatments for their effect on trap catches. Like kairomone experiment, the treatments were replicated ten times and the trap catches were sexed and counted every week for five weeks.

\section{Yeast and ethyl acetate}

In the final experiment, four treatments were tested to assess the effect on trap catches due to addition of yeast to date fruits with and without ethyl acetate, which was compared with date fruits alone and in combination with ethyl acetate. The standard Saudi trap components were altered as per the four treatments except lure, water, insecticide and date fruits. Apart from (i) date fruits alone, three other combinations, (ii) date fruits with ethyl acetate, (iii) date fruits with yeast, and (iv) date fruits with yeast and ethyl acetate, were tested for six weeks and replicated ten times. Trap catches were sexed and counted.

\section{Statistical analysis}

All statistical analyses were performed using SPSS (SPSS Release 16.00). The data was evaluated for the normality and homoscedasticity (Homogeneity of variance test, $P<0.05)$ and required no transformation for the analyses. All trap capture data were presented as mean \pm standard error and subjected to one-way ANOVA. The means were separated using Tukey's multiple test. The mean differences were considered significant at values $P<0.05$ level. The confidence limit was $95 \%$. To assess the statistical difference in the trap catches due to type of traps, an independent samples t-test was performed with significance level set at $P<0.05$.

\section{RESULTS AND DISCUSSION}

\section{Stump trap}

This experiment lasted for 12 weeks. In the first four weeks, the stump trap catches were higher than the tree traps but not significantly as revealed by the t-test data of week $2(t=1.976$; df $=24 ; P=0.060$ (and week $4(t=$ 1.495; df $=24 ; P=0.148$ ) (Fig. 1). However, the stump trap catches emerged significantly superior to the tree trap in week $6(t=2.732 ; \mathrm{df}=24 ; P<0.05)$, week $8(t=$ 2.406; $\mathrm{df}=24 ; P<0.05)$, week $10(t=2.695 ; \mathrm{df}=24 ; P<$ $0.05)$ and week $12(t=2.465 ; \mathrm{df}=24 ; P<0.05)$. The total stump trap catches (mean $=9.91 \pm 0.45)$ in 12 weeks were significantly higher $(t=5.451 ; \mathrm{df}=154 ; P<0.05)$ than the total tree trap catches (mean $=6.33 \pm 0.47$ ). Notably, stump trap preparation demanded comparatively more effort due to handling and transportation. Once located, they were easy to install and service. Tree traps are more common due to their cost and handling ease. In Indonesia and United Arab Emirates, tree traps have been recommended (Hallett 


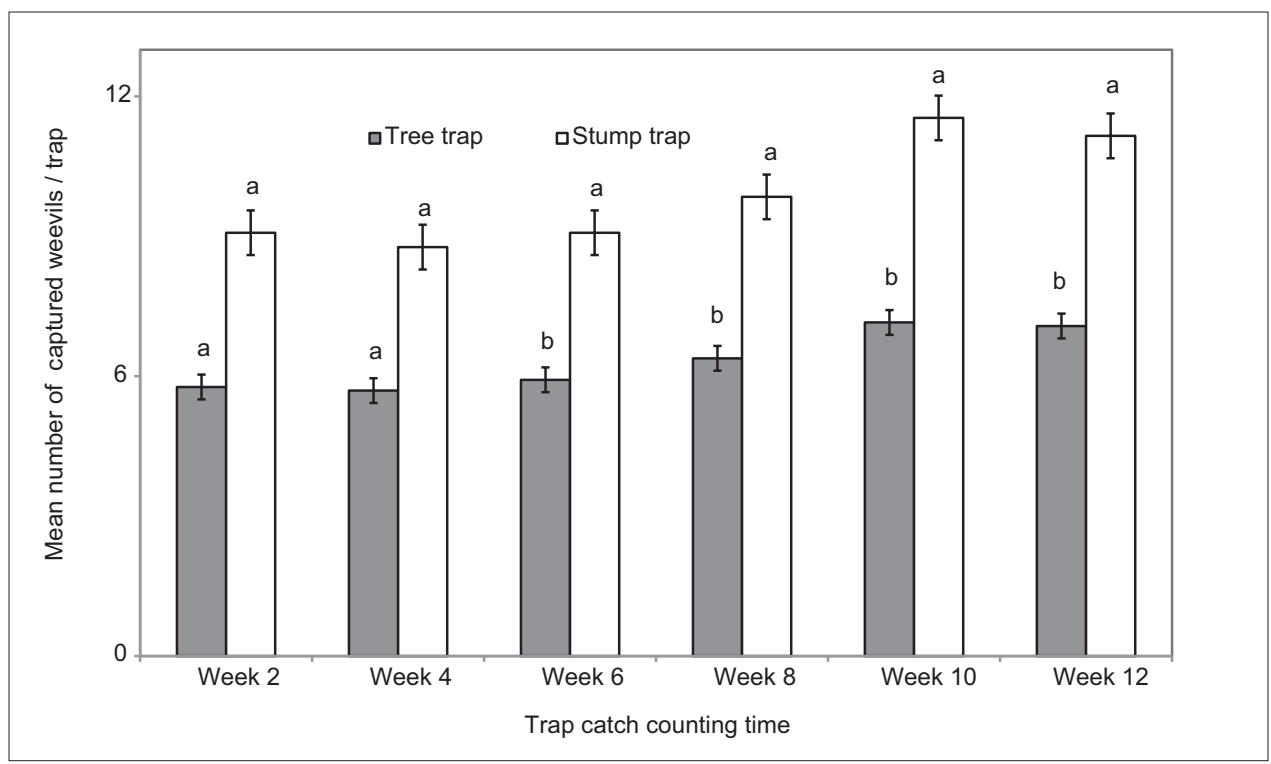

Fig 1. Mean number of weevils captured per trap in tree and stump traps. Bars labeled with different letters are significantly different at $P<0.05$ (independent samples t-test).

et al., 1993b). In case of tree traps, trap height from the ground level is an important consideration. In coconut plantations in India, $1.0 \mathrm{~m}$ height was reported to yield highest trap catches (Faleiro, 2005). In India, Muralidharan et al. (1999) hung the bucket traps on date palm trees at breast height, whereas in Sri Lanka, Rajapakse et al. (1998), chose $1.5 \mathrm{~m}$ height above ground to hang traps on coconut trees for mass trapping studies on RPW. In Saudi Arabia, $1.5 \mathrm{~m}$ height was recommended for placing pheromone traps on date palm trunks (Abraham et al., 1998). As high as $3 \mathrm{~m}$ height has been reported for tethering traps on date palm trunks in Egypt (El-Garhy, 1996). On the contrary, ground level traps on coconut palms were found to be most effective with maximum trap catches in Indonesia (Hallet et al., 1999). It is important to note that placing the traps on young palm trees can potentially invite infestation (Faleiro, 2006). In order to avoid infestation in trees used for hanging pheromone traps, ground level traps away from the trees have been suggested (Hunsberger et al., 2000). For example, Oehlschlager (2006) suggested for Middle-eastern region to partially bury the pheromone traps in the ground away from the tree. Trap windows at ground level allow easier insect entry. Ground level traps are being used in several countries including Israel, Spain and UAE (Faleiro, 2006). Stump traps used in the present study, allow trap placement away from the tree and thus avoid or at least alleviate the potential risk of inviting infestation. Secondly, stump traps have easy accessibility from all sides for flying weevils and they are easier to service due to their position away from the tree and at nearly waist height. In addition, the stump provides a landing and climbing platform to weevils trying to trace the lure source. Thus, like buried ground traps where trap windows are at the ground level, in case of stump traps too, weevils don't need to climb steeply against gravity and can walk almost straight into the trap. But unlike ground traps, stump traps not subject to drainage from rain or irrigation water and are less likely to be damaged by workers accidentally or foraging animals. Notably, despite the stumps being insecticide-treated dead fibrous wood, the present study does not claim that no volatiles are produced by the stumps. Additionally, in pursuit of placing the stumps between the two tree rows, difficulty was faced sometimes in finding shaded spots for them. Although the release rate of the lures was not ascertained in the present study, it has been suggested previously that pheromone longevity is adversely affected if the traps are placed in direct sunlight (Faleiro et al., 1998).

\section{Pheromone lure}

The RPW pheromone lures have been used effectively in coconut and date plantations since the launch of first commercial product in the year 1994 as Ferrolure (Chem Tica International, Costa Rica). Many studies have reported lure comparison tests and most of them have included Ferrolure ${ }^{\mathrm{TM}}$ as one of the tested lures. In the present study, no significant difference was observed between the weekwise trap catches of the three commercially available pheromone lures, Ferrolure+ ${ }^{\mathrm{TM}}$, RHYFER ${ }^{\mathrm{TM}}$ and RHYNCAPTM (df=2, 44; F=1.498; $P=0.235$ ) (Table 1), despite the differences in their dispensers. Similarly, a recent study reported comparison of four lures where no statistically significant difference in the trap catches from Ferrolure ${ }^{\mathrm{TM}}$ was found when compared to three other commercially available pheromone lures, Pherobank RPW lure (Pherobank), IT189 ISCA ${ }^{\text {TM }}$ Lure-ferrugineus (ISCA Technologies) and Rhylure ${ }^{\mathrm{TM}}$ WAT-700 (Russel 
Abdel-Azim, et al.: Trap contents and placement for red palm weevil

Table 1: Mean number of weevils captured every two weeks in standard Saudi traps baited with Ferrolure $+^{\mathrm{TM}}$, $\mathrm{RHYFER}^{\mathrm{TM}}$ or $^{\mathrm{T}}$ RHYNCAPTM pheromone lures

\begin{tabular}{lcccccc}
\hline Treatment & \multicolumn{5}{c}{ Mean No. of Weevils/Trap/2 weeks } \\
\cline { 2 - 6 } & Week 2 & Week 4 & Week 6 & Week 8 & Week 10 & Total \\
\hline${\text { Ferrolure }{ }^{\text {TM }}}^{\text {Thy }}$ & $7.67 \pm 2.03$ & $8.00 \pm 2.65$ & $4.00 \pm 2.08$ & $14.00 \pm 2.52$ & $11.00 \pm 3.46$ & $8.93 \pm 1.33$ \\
RHYFER $^{\text {TM }}$ & $3.33 \pm 0.33$ & $6.67 \pm 3.38$ & $3.67 \pm 1.45$ & $12.67 \pm 2.33$ & $9.00 \pm 4.51$ & $7.07 \pm 1.41$ \\
RHYNCAP $^{\text {TM }}$ & $2.67 \pm 0.33$ & $8.00 \pm 2.08$ & $3.00 \pm 0.01$ & $8.33 \pm 1.67$ & $7.67 \pm 2.33$ & $5.93 \pm 0.91$ \\
F, P value & $5.103,0.051$ & $0.078,0.926$ & $0.121,0.888$ & $1.809,0.243$ & $0.224,0.806$ & $1.498,0.235$ \\
\hline
\end{tabular}

Mean \pm SE numbers significantly different at $P<0.05$ (ANOVA, Post hoc by Tukey's test)

IPM) despite the Rhylure ${ }^{\mathrm{TM}}$ sharing similar dispensing mechanism with Ferrolure+TM (El-Shafie and Faleiro, 2017). On the other hand, Ferrolure ${ }^{\mathrm{TM}}$ was reported to be significantly better in catches when compared to the two-component (ferrugineol and ferrugineone) lures from Qualiube company, France and Sedq company, Spain (Abbas and Al-Nasser, 2012) or when compared to four lures containing four enantiomers of 4-methyl-5-nonanol (SciTech, Czech Republic and IPM Technologies, USA) (Kaakeh et al., 2001). Similarly, Faleiro and Chellapan (1999) reported significantly more Ferrolure ${ }^{+{ }^{T M}}$ trap catches than lure of Agrisense, UK from coconut plantation in India. But in Saudi Arabia, Ferrolure ${ }^{\text {TM }}$ trap catches were found at par with lure of Agrisense, UK, though significantly more than Calliope lure formulation from France (Faleiro et al., 2000). However, Interestingly, only major component (ferrugineol) based pheromone lures are also available commercially, as role of ferrugineone is not clear. Although in Saudi Arabia, it was shown that the minor presence of 4-methyl-5-nonanone along with 4-methyl-5-nonanol significantly increases the trap catches (Abozuhairah et al., 1996; Oehlschlager, 2006), the role of ketone component in augmenting the catches is debated (Vacas et al., 2017). Nevertheless, many two-component formulations of the RPW pheromone lure are still available commercially.

\section{Lure and ethyl acetate}

The objective of the second experiment was to test the role of kairomone, ethyl acetate in synergizing the RPW attraction of pheromone lure - food bait combination, and thus augmenting the trap catches. Ferrolure ${ }^{+{ }^{T M}}$ and RHYFER ${ }^{\mathrm{TM}}$ were chosen for this experiment as they performed slightly better over the third lure, RHYNCAPTM in the first experiment (Table 1). The trap catches from Ferrolure+ ${ }^{\mathrm{TM}}$ and RHYFER ${ }^{\mathrm{TM}}$ were not significantly different from each other. But when their combinations with ethyl acetate were compared, Ferrolure ${ }^{+\mathrm{TM}}$ with ethyl acetate attracted significantly more number of weevils than the RHYFER ${ }^{\mathrm{TM}}$ and ethyl acetate combination in the first week and also in total of four-week catches ( $\mathrm{df}=3,143 ; F=38.022$; $P<0.0001)$. When trap catches from pheromone alone were compared with their ethyl acetate combinations, the Ferrolure ${ }^{\mathrm{TM}}$ and ethyl acetate combination showed highly significant increase in the trap catches in each of the four weeks as well as in mean of the total catches for the entire experiment. The RHYFER ${ }^{\mathrm{TM}}$ and ethyl acetate combination also showed similarly significant increase in trap catches over pheromone lure alone, except in the week 3 when the trap catches were not significantly different. Overall, combination of Ferrolure ${ }^{+\mathrm{TM}}$ with ethyl acetate attracted maximum weevils amongst the four tested treatments (Fig. 2).

Many studies have found ethyl acetate synergizing the lure-food bait attraction of RPW (Oehlschlager, 1998; El-Sebay, 2003; Al-Shagag et al., 2008; Guarino et al., 2011; Al-Saoud, 2013; Giblin-Davis et al., 2013; Vacas et al., 2014, 2017). For example, in a latest study using food-baited wet bucket trap and a commercial product, Weevil Magnet ${ }^{\mathrm{TM}}, \mathrm{Al}$ Saoud (2013) showed that mean monthly RPW trap catches from ethyl acetate and lure combination were $\sim 1.6$ times higher than the traps without ethyl acetate. Similarly, in a comparison between Ferrolure ${ }^{+\mathrm{TM}}$ with and without ethyl acetate, 3 and 4 times higher trap catches for female and male weevils were reported, respectively, when ethyl acetate was present (Solaiman and Abd El-Latif, 2013). However, it is important to note that ethyl acetate is not a substitute of food (Faleiro, 2006). Vacas et al. (2013) in experiments with Picusan ${ }^{\circledR}$ trap (Sansan Prodesing SL, Naquera, Valencia, Spain), showed that ethyl acetate doesn't synergizes the lure attraction in absence of food bait and alone it can't be considered for replacing the food bait. This in turn suggests obligatory and synergistic significance of additional kairomonal volatiles and their respective ratios from food bait apart from ethyl acetate. Therefore, though ethyl acetate is still considered indispensable as a co-attractant, efforts are targeted towards its combinations with other food fermentation volatiles, including ethanol, to replace the plant material in the trap (Vacas et al., 2017). Notably, apart from the lure-bait synergism by ethyl acetate for attracting RPW, the present study revealed subtle but significant differences in synergistic role of ethyl acetate for lures differing in the dispensing matrix. The differences in lure attraction may depend on two desired attributes: (i) stable release rate in the 4 to $5 \mathrm{mg}$ per day range, and (ii) longevity (which includes longer chemical stabilization of the components). The sustained release of pheromone may affect the performance of the lure over the lifetime of the sachet. In the presence of a co-attractant and/or 
food kairomones, difference in the lure performance is magnified.

\section{Kairomone}

Four kairomones/combination were evaluated in the fourth field experiment. The total trap catch count showed ethyl acetate and acetic acid alone and together as the most effective co-attractants ( $\mathrm{df}=4,449 ; F=8.486 ; P<0.0001$ ). Ethanol was found to be the most feeble attractant amongst the tested kairomones. In the male - female segregated counts too, the combination of ethyl acetate and acetic acid attracted maximum weevils but not significantly more than either of them alone $(\mathrm{df}=4,249 ; F=5.956 ; P<0.0001$ and $\mathrm{df}=4,249 ; F=3.963 ; P<0.001$ for female and male adults, respectively). Ethanol though showed less trap catches of segregated adults than ethyl acetate and acetic acid but not became an exception to attracting more female than the male adults. Compared to control, ethanol attracted twice female adults (Table 2).

The combination of aggregation pheromone with host kairomones have been reported to synergize the attractiveness for R. ferrugineus (Hallett et al., 1993a,b). The salient findings from the kairomone experiment of the present study endorsed both ethyl acetate and acetic acid as potential candidates for further evaluation. Acetic acid has previously been implicated as potential RPW kairomone in trapping studies done on Coconut (Kurian et al., 1984; Faleiro, 2005). It has been detected as a major component of sugarcane volatiles (Rochat et al., 2000) and from the infested Canary Island Palm (Phoenix canariensis) stem under anaerobic conditions and was shown to elicit high antennal response on electro-antennogram detector (Vacas et al., 2014). Additionally, in both the quoted studies, ethyl acetate and ethanol blends were tested as kairomonal mixtures to find the synergistic co-attractant composition for food bait-free traps. Interestingly, what Rochat et al. (2000) reported 16 years ago in their seminal study on the efficiency of ethyl acetate - ethanol blends for R. palmarum, was verified 14 years later by Vacas et al. (2014) in case of R. ferrugineus. In a recent multi-location study, ethanol-biased blend with ethyl acetate augmented the catches in food bait-free traps from 1.4 to 2.2 times (Vacas et al., 2017). Based on the results of the present

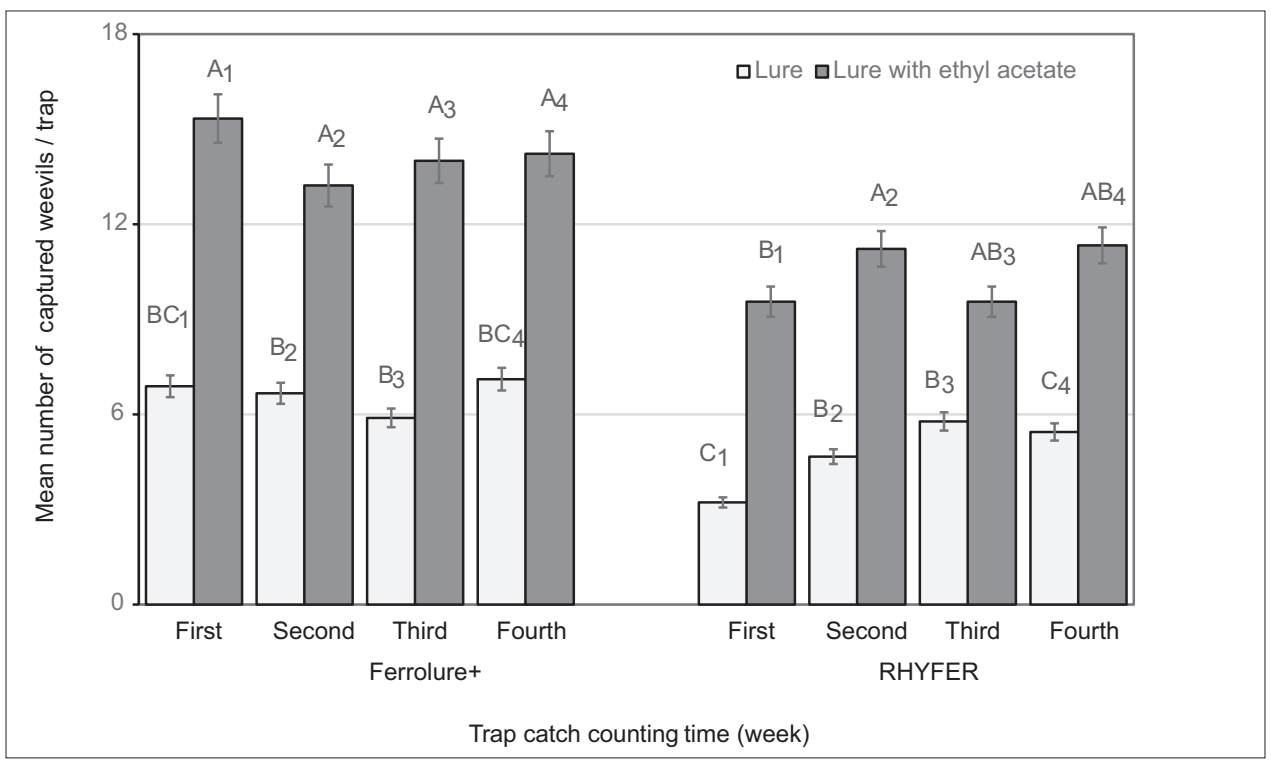

Fig 2. Mean number of weevils captured in traps baited with Ferrolure+ ${ }^{\mathrm{TM}}$ or RHYFER ${ }^{\mathrm{TM}}$ pheromone lures with or without ethyl acetate. Bars labeled with different letters are significantly different at $P<0.05$ (ANOVA, Post hoc by Tukey's test). Letters with same number-subscript are comparable (week-wise).

Table 2: Mean number of female and male weevils captured in standard Saudi traps baited with different kairomones

\begin{tabular}{|c|c|c|c|c|}
\hline \multirow{2}{*}{ Treatments } & \multicolumn{3}{|c|}{ Mean No. of Weevils/Trap } & \multirow{2}{*}{$\begin{array}{c}\text { Sex Ratio } \\
\text { (Female/male) }\end{array}$} \\
\hline & Female & Male & Total & \\
\hline Ethyl Acetate & $2.76 \pm 0.32 \mathrm{ab}$ & $1.48 \pm 0.20 \mathrm{ab}$ & $2.12 \pm 0.20^{a}$ & 1.9 \\
\hline Acetic Acid & $3.06 \pm 0.35$ ab & $1.44 \pm 0.18$ ab & $2.25 \pm 0.21^{a}$ & 2.1 \\
\hline Ethyl Acetate+Acetic Acid & $3.32 \pm 0.37^{a}$ & $1.72 \pm 0.25^{a}$ & $2.52 \pm 0.24^{a}$ & 1.9 \\
\hline Ethanol & $2.00 \pm 0.17 \mathrm{bc}$ & $0.94 \pm 0.11^{b}$ & $1.47 \pm 0.11^{b}$ & 2.1 \\
\hline Control & $1.06 \pm 0.21^{\mathrm{c}}$ & $0.90 \pm 0.13^{b}$ & $1.25 \pm 0.13^{b}$ & 1.8 \\
\hline$F, P$ value & $5.956,0.000$ & $3.963,0.004$ & $8.486,0.000$ & \\
\hline
\end{tabular}

Mean \pm SE numbers labeled with different letters are significantly different at $P<0.05$ (ANOVA, Post hoc by Tukey's test) 
study, the blends of ethyl acetate, acetic acid and ethanol can be tried in different ratios. The release rates were not recorded in the present experiment. However, ethanol emissions were higher than ethyl acetate as ethanol needed refill every 2 weeks whereas ethyl acetate and water were refilled back to $10 \mathrm{ml}$ mark in the third week. Acetic acid needed refilling in the fourth week.

\section{Food bait}

Amongst the three food baits evaluated, date fruits attracted maximum number of weevils however not significantly different from the numbers attracted by date stem or sugarcane pieces. The same trend was observed in the female and male catches too. The difference between the food baits became significant, interestingly, in presence of ethyl acetate. The total catch of adult weevils in the traps having date fruits with ethyl acetate was recorded significantly higher $(\mathrm{df}=5,599 ; F=7.304 ; P<0.0001)$ than the traps having date stem or sugarcane pieces with ethyl acetate. Significantly more female adults were attracted towards date fruit + ethyl acetate combination than sugarcane with ethyl acetate but date stem pieces with ethyl acetate combination attracted similar numbers ( $\mathrm{df}$ $=2$, 299; $F=4.981 ; P<0.0001)$. However, male catches were not different between the respective combinations of three tested food baits and ethyl acetate ( $\mathrm{df}=5,299$; $F=3.062 ; P<0.010)$. In addition, the female adult catches in case of date fruits with or without ethyl acetate were not different but the difference became significant in case of total adult catches. On the other hand, amongst the tested food baits, date palm stem pieces or sugarcane pieces alone were found to be significantly weaker attractants (Table 3).

The role of host plant tissues as food bait in synergizing the attraction by aggregation pheromones has been reported in many Rhynchophorus sp. including $R$. ferrugineus (Hallet et al., 1999), R. phoenicis F. (Gries et al., 1994), R. cruentatus F. (Weissling et al., 1994) and R. palmarum (Jaffe et al., 1993). Before discussing food baits, it is important to highlight that food bait without lure has been reported to be ineffective (Oehlschlager et al., 1993; Faleiro \& Chellapan, 1999; Hallett et al., 1999). The bait-lure synergy for RPW attraction has been discussed before for date fruits (Faleiro, 2005), date palm stem pieces (Anonymous, 1998; Hallett et al., 1999) and sugarcane (Oehlschlager, 1994; Faleiro and Chellapan, 1999). However, in order to synergize the lure, Oehlschlager (2006) argued that food bait should contain high sugar content. As a matter of fact, date fruits boast of over 50 per cent sugar content (Zhang et al., 2015) against less than 20 per cent in case of sugarcane (Srichayet et al., 2008). When compared to date fruits, the weaker attraction by sugarcane observed in the present study, corroborates the argument. For example, in their field trial experiments with lure, co-attractant ethyl acetate and food bait, Azmi et al. (2014) reported sugarcane stem pieces to be a weaker attractant compared to Sago palm stem pieces (and pineapple fruit pieces) in a coconut plantation. Nevertheless, sugarcane has been widely reported as an effective food bait for palm weevils (Oehlschlager et al., 1993; Muralidharan et al., 1999; Nair et al., 2000; Muthiah et al., 2005). However, in the MiddleEast region, fodder-grade date fruits are preferred over sugarcane and date palm stem pieces due to its high synergy with lure and easy availability (Abraham et al., 1999; Faleiro, 2000; Oehlschlager, 2006; Abuagla and Al-deeb, 2012). Like the present study, Faleiro and Satarkar (2005) compared dried date fruits and sugarcane as food baits and reported no statistical difference in their respective trap catches. Date palm stem pieces along with date fruits were used in the Al-Ahsa region of Saudi Arabia between the years 1994 and 1998 for mass trapping the RPW (Anonymous, 1998). Notably, the results of the food bait experiment in the present study showed no difference between the three tested food baits. However, an important finding which emerged from this experiment underlines the third important factor, co-attractant. Intriguingly, synergy between mutually exclusive components of the trap like food bait, lure and kairomone emerged as an important factor in augmenting the trap catches. The presence of ethyl acetate significantly differentiated between catches of traps with date fruits and rest of the two food baits, thus upgrading the synergistic coupling of bait-lure to co-attractant-bait-lure system. This finding corroborates the authors' previous field observations which repeatedly pointed towards rather holistic evaluation of the trap than the evaluation of its disparate elements. The use of ethyl

Table 3: Mean number of female and male weevils captured in pheromone traps baited with different plant materials

\begin{tabular}{|c|c|c|c|c|}
\hline \multirow[t]{2}{*}{ Treatments } & \multicolumn{3}{|c|}{ Mean no. of weevils/trap } & \multirow{2}{*}{$\begin{array}{c}\text { Sex Ratio } \\
\text { (Female/male) }\end{array}$} \\
\hline & Female & Male & Total & \\
\hline Date Stem & $1.08 \pm 0.14^{b}$ & $0.60 \pm 0.12^{b}$ & $0.84 \pm 0.10^{b}$ & 1.8 \\
\hline Date Fruits & $1.66 \pm 0.23 \mathrm{ab}$ & $0.82 \pm 0.12 \mathrm{ab}$ & $1.24 \pm 0.14^{b}$ & 2.0 \\
\hline Sugarcane & $1.00 \pm 0.13^{b}$ & $0.54 \pm 0.11^{b}$ & $0.77 \pm 0.09 \mathrm{~b}$ & 1.9 \\
\hline Date Stem+Ethyl Acetate & $1.60 \pm 0.21 \mathrm{ab}$ & $0.76 \pm 0.15 \mathrm{ab}$ & $1.18 \pm 0.13^{b}$ & 2.1 \\
\hline Date Fruits+Ethyl Acetate & $2.18 \pm 0.24^{a}$ & $1.22 \pm 0.16^{a}$ & $1.70 \pm 0.15^{\mathrm{a}}$ & 1.8 \\
\hline Sugarcane+Ethyl Acetate & $1.36 \pm 0.19^{b}$ & $0.72 \pm 0.15^{a b}$ & $1.04 \pm 0.12^{b}$ & 1.9 \\
\hline$F, P$ value & $4.981,0.000$ & $3.062,0.010$ & $7.304,0.000$ & \\
\hline
\end{tabular}

Mean \pm SE numbers labeled with different letters are significantly different at $P<0.05$ (ANOVA, Post hoc by Tukey's test) 
acetate as co-attractant along with lure and food bait is widely known, practiced and recommended (Oehlschlager et al., 1993; Hallett, 1996; Hallett et al., 1999; Faleiro and Kumar, 2008; Al-Saoud et al., 2010; Roda et al., 2011). However, discovery of the other key odorants synergizing attraction will help in development of standardized and optimized synthetic synergist or a blend to optimize kairomonal effect without using plant material (Guarino et al., 2011; Vacas et al., 2014).

\section{Yeast and ethyl acetate}

Fermenting food baits are known to sustain high RPW trap catches (Hallett et al., 1999; Oehlschlager, 2016). Fermentation of food generates more variety of volatiles with their increased output (Rochat et al., 2000). Therefore in this experiment, faster fermenting date fruits due to the addition of yeast were tested to know if consequent increase in variety and amount of date fruit volatiles help in augmenting and sustaining the RPW pheromone trap catches. The respective female and male trap catches from date fruits alone were comparable with traps having both date fruits and yeast. However, the total trap catches from date fruits with yeast were significantly higher than date fruits alone (Table 4). On the other hand, El-Shafie and Faleiro (2017) recently reported no significant differences in trap catches in case of date fruits with or without yeast. Notably, the quoted study was done with two species of yeasts produced from date syrup at Date Palm Research Center of Excellence, King Faisal University, Saudi Arabia. The scope of the present study was extended further by adding a known fermenting food volatile, ethyl acetate to know if it further synergizes the RPW attraction by lure in presence of food bait and yeast. The date fruits with ethyl acetate afforded significantly higher individual female and male, and also the total trap catches than from date fruits alone $(\mathrm{df}=3,79 ; F=16.752 ; P<0.0001)$. Moreover, the faster fermenting date fruits may have compensated for the presence of ethyl acetate as the higher trap catches from the combination of date fruits with ethyl acetate were not statistically significant from their combination with yeast. However, the combination of date fruits with yeast or ethyl acetate could not match the trap catches from the combination of all three. Faster fermenting date fruits due to yeast in presence of ethyl acetate release source imparted significantly higher attraction to the lure as evident from the total and individual gender trap catches $(\mathrm{df}=3,39 ; \mathrm{F}=$ 11.969; $P<0.0001$ and $\mathrm{df}=3,39 ; F=12.934 ; P<0.0001$ for female and male adults, respectively). One exception to the overall superiority of date fruits + yeast + ethyl acetate combination was male catches, which were not significantly ahead of male catches from date fruits + ethyl acetate combination. Nevertheless, the results clearly indicate that in the presence of ethyl acetate, fast fermenting date fruits become more attractive to RPW weevils (Table 4). Kurian et al. (1984) reported use of yeast with toddy (locally made alcoholic drink from coconut) in presence acetic acid to get maximum RPW catches. In a study on RPW attraction by food baits, the trap catches from coconut petioles were found to be similar with or without yeast, but in presence of acetic acid, combination of coconut petioles, toddy and yeast attracted higher number of weevils (Faleiro, 2005). Interestingly, Rochat et al. (2000) reported acetic acid as a major component of sugarcane and not coconut volatiles.

The trap catches in kairomone, food bait and yeast experiments were invariably female biased (Tables 2-4). Many previous studies have also reported female biased sex ratios in the pheromone trap catches (Abraham et al., 1999; Faleiro and Rangnekar, 2000; Vidyasagar et al., 2000a; Al-Saoud, 2011; Faleiro and Satarkar, 2003a; Soroker et al., 2005, Avalos and Soto, 2015). Although, a few studies (Hallett et al., 1993a; Muralidharan et al., 1999; Abbas et al., 2006) have reported no significant difference between male and female trap catches. In fact, if the trap catches are female biased, it is a significantly advantageous because each female adult captured counts towards reducing population buildup and preventing spread of infestation as most female adults recovered from pheromone traps have been reported to be young and gravid (Abraham et al., 2001; Faleiro et al., 2003). Thus, this makes masstrapping programs an important tool in the IPM of RPW. In contrast, a few studies have disputed female-bias in the RPW population, both in laboratory cultures (Poorjavad et al., 2009; Al-nujiban et al., 2015) and field studies (Abbas et al., 2006). This presents intriguing research opportunity largely overlooked so far (Soroker et al., 2005).

Table 4: Mean number of female and male weevils captured in pheromone traps baited with date fruit with and without ethyl acetate and yeast.

\begin{tabular}{|c|c|c|c|c|}
\hline \multirow[t]{2}{*}{ Treatments } & \multicolumn{3}{|c|}{ Mean no. of weevils/trap } & \multirow{2}{*}{$\begin{array}{c}\text { Sex Ratio } \\
\text { (Female/male) }\end{array}$} \\
\hline & Female & Male & Total & \\
\hline Date fruit & $3.03 \pm 0.34^{c}$ & $1.67 \pm 0.27^{c}$ & $2.35 \pm 0.26^{c}$ & 1.82 \\
\hline Date fruit+Ethyl acetate & $5.69 \pm 0.46^{b}$ & $3.70 \pm 0.46$ ab & $4.70 \pm 0.39^{b}$ & 1.54 \\
\hline Date fruit+Yeast & $4.75 \pm 0.82 \mathrm{bc}$ & $2.77 \pm 0.44 \mathrm{bc}$ & $3.76 \pm 0.51^{b}$ & 1.72 \\
\hline Date fruit+Yeast+Ethyl acetate & $7.67 \pm 0.50^{a}$ & $4.98 \pm 0.36{ }^{a}$ & $6.32 \pm 0.43^{a}$ & 1.54 \\
\hline$F, P$ value & $11.969,0.000$ & $12.934,0.000$ & $16.752,0.000$ & \\
\hline
\end{tabular}

Mean \pm SE numbers labeled with different letters are significantly different at $P<0.05$ (ANOVA, Post hoc by Tukey's test) 


\section{CONCLUSION}

The present study highlighted several important aspects of RPW pheromone trapping system in the areas of trap placement and semiochemicals. Higher counts of weevil catches from stump trap broaden the areas of considerations in trap placement decisions than merely height from the ground. The masked differences in the lure performance become obvious in the presence of kairomones such as ethyl acetate. The first field-use of acetic acid as pheromone synergist in date palm gave encouraging results and deserves further probe. Differences in attraction of RPW adults by the food materials is another outcome of the present study which needs further exploration. Like lures, food baits also showed differences when combined with ethyl acetate and/or yeast. The coattractants therefore, are the key trap components and new discoveries in co-attractant combinations as lure synergists may lead the way towards food-bait free trap. Results from the present study further strengthen the rational and environment-benign IPM components like pheromone trapping and also underline the researchable areas to tweak the traditional trapping protocols for RPW management.

\section{ACKNOWLEDGEMENTS}

This research was supported by Grants-in-aid for Scientific Research No. 11-AGR1477-02, King Abdul Aziz City for Science and Technology - National Plan for Science, Technology and Innovation (KACST-NSTIP) (MAARIFAH), Saudi Arabia. We also thank KSU - Deanship of Scientific Research, Research Chair Program, King Saud University, Saudi Arabia. We also thank Samy M. M. Ibrahim of Chair of Date Palm Research (CDPR) for providing technical support.

\section{Authors' contribution}

PSPVV and SAA designed, organized and supervised the original experiments modified later by MMA and PS. MMA, RM and PS carried out the experiments and collected the data. MMA analyzed the data with inputs from PS. PS wrote the paper with inputs from MMA.

\section{REFERENCES}

Abbas, M. K. and A. Al-Nasser. 2012. Ecological studies and evaluation of some aggregation pheromone types with measuring the potential of female reproductive system in red palm weevil, Rhynchophorus ferrugineus (Olivier). Nat. Sci. 10(12): 188-193.

Abbas, M. S. T., S. B. Hanounik, A. S. Shahdad and S. A. Al-Bagham. 2006. Aggregation pheromone traps, a major component of IPM strategy for the red palm weevil, Rhynchophorus ferrugineus, in date palms (Coleoptera: Curculionidae). J. Pest Sci. 79: 69-73.

Abdallah, F. F. and S. A. Al-Khatri. 2005. The effect of pheromone, kairomone and food bait on attracting males and females of red palm weevil. Egypt. J. Agric. Res. 83(1): 169-177.

Abdel-Azim, M. M., R. Khan, S. A. Aldosari, P. S. P. Vidyasagar, S. Ibrahim and P. Shukla. 2014. Studies for colour-selection of Rhynchophorus ferrugineus pheromone trap. J. Plant. Crops. 42(3): 386-391.

Abozuhairah, R. A., P. S. P. Vidyasagar and V. A. Abraham. 1996. Integrated Management of Red Palm Weevil, Rhynchophorus ferrugineus F. In Date Palm Plantations of the Kingdom of Saudi Arabia. In: Proceedings of the $20^{\text {th }}$ International Congress on Entomology, 25-31 August, Firenze, Italy. p. 541.

Abraham, V. A., M. A. Al-Shuaibi, J. R. Faleiro, R. A. Abozuhairah and P. S. P. Vidyasagar. 1998. An integrated management approach for red palm weevil, Rhynchophorus ferrugineus Oliv. A key pest of date palm in the middle East. Agric. Sci. 3: 77-83.

Abraham, V. A., J. R. Faleiro, M. A. Al-Shuaibi and S. Al-Abdan. 2001. Status of pheromone trap captured female red palm weevils from date gardens in Saudi Arabia. J. Trop. Agric. 39: 197-199.

Abraham, V. A., J. R. Faleiro, M. A. Al-Shuaibi and T. P. Kumar. 2000. A strategy to manage red palm weevil Rhynchophorus ferrugineus Oliv. on date palm Phoenix dactylifera L. its successful implementation in Al-Hassa, Kingdom of Saudi Arabia. Pestology. 24(12): 23-30.

Abraham, V. A., J. R. Faliero, T. P. Kumar and M. A. Al-Shuaibi. 1999 Sex ratio of red palm weevil Rhynchophorus ferrugineus Oliv., captured from date plantations of Saudi Arabia using pheromone (Ferrolure) traps. Indian J. Entomol. 61(2): 201-204.

Abraham, V. A., S. S. Nair and C. P. R. Nair. 1999. A comparative study on the efficacy of pheromone lures in trapping red palm weevil, Rhynchophorus ferrugineus Oliv. (Coleoptera: Curculionidae) in coconut gardens. Indian Coconut J. 30: 1-2.

Abuagla, A. M. and M. A. Al-Deeb. 2012. Effect of bait quantity and trap color on the trapping efficacy of the pheromone trap for the red palm weevil Rhynchophorus ferrugineus. J. Insect Sci. 12: 120.

Al-Dosary, N. M. N., S. Al-Dobai and J. R. Faleiro. 2016. Review on the management of red palm weevil Rhynchophorus ferrugineus Olivier in date palm Phoenix dactylifera L. Emir. J. Food Agric. 28(1): 34-44.

Al-Nujiban, A. A., S. A. Aldosari, A. M. Al Suhaibani, M. M. Abdel-Azim, S. M. M. Ibrahim and P. Shukla. 2015. Effect of date palm cultivar on fecundity and development of Rhynchophorus ferrugineus. Bull. Insectol. 68(2): 199-206.

Al-Saoud, A. H. 2011. Comparative effectiveness of four food baits in aggregation pheromone traps on red palm weevil Rhynchophorus ferrugineus Olivier. Arab J. Plant Prot. 29(1): 83-89.

Al-Saoud, A. H. 2013. Effect of ethyl acetate and trap colour on weevil captures in red palm weevil Rhynchophorus ferrugineus (Coleoptera: Curculionidae) pheromone traps. Int. J. Trop. Insect Sci. 33(3): 202-206.

Al-Saoud, A. H., M. A. Al-Deeb and A. K. Murchie. 2010. Effect of color on the trapping effectiveness of red palm weevil pheromone traps. J. Entomol. 7(1): 54-59.

Al-Shagag, A., A. H. Al-Abbad, A. M. Al-Dandan, A. Abdallah and J. R. Faleiro. 2008. Enhancing trapping efficiency of red palm weevil pheromone traps with ethyl acetate. Indian J. Plant Prot. 36: 310-311.

Anonymous. (1998). Final Report of the Indian Technical Team (Part)A), Red Palm Weevil Control Project, Ministry of Agriculture and Water, Kingdom of Saudi Arabia, pp. 1-65.

Avalos, J. A. and A. Soto. 2015. Study of chromatic attraction of the red palm weevil, Rhynchophorus ferrugineus using bucket traps. 
Bull. Insectol. 68(1): 83-90.

Avand, F. A. 1996. The biology of red palm weevil, Rhynchophorus ferrugineus Oliv. (Coleoptera: Curculionidae) in Saravan region (Sistan and Balouchistan Province, Iran). Appl. Entomol. Phytopath. 63: 16-18.

Azmi, W. A., S. N. Daud, M. H. Hussain, Y. K. Wai, Z. Chik and A. S. Sajap. 2014. Field trapping of adult red palm weevil Rhynchophorus ferrugineus Olivier (Coleoptera: Curculionidae) with food baits and synthetic pheromone lure in a coconut plantation. Philipp. Agric. Sci. 97(4): 409-415.

Dembilio, O., E. Quesada-Moraga, C. Santiago-Alvarez and J. A. Jacas. 2010. Biocontrol potential of an indigenous strain of the entomopathogenic fungus Beauveria bassiana (Ascomycota; Hypocreales) against the red palm weevil, Rhynchophorus ferrugineus (Coleoptera: Curculionidae). J. Invert. Path. 104: 214-221.

El-Garhy, M. E. 1996. Field evaluation of the aggregation pheromone of Rhynchophorus ferrugineus in Egypt. Brighton Crop Prot. Conf. Pest. Dis. 3: 18-21.

El-Sabea, A. M. R., J. R. Faleiro and M. M. Abo El-Saad. 2009. The threat of red palm weevil Rhynchophorus ferrugineus to date plantations of the Gulf region of the Middle East: An economic perspective. Outlook Pest. Manag. 20: 131-134.

El-Sayed, A. M., D. M. Suckling, C. H. Wearing and J. A. Byers. 2006. Potential of mass trapping for long-term pest management and eradication of invasive species. J. Econ. Entomol. 99: 1550-1564.

El-Sebay, Y. 2003. Ecological studies on the red palm weevil Rhynchophorus ferrugineus Oliv., (Coleoptera: Curculionidae) in Egypt. Egypt. J. Agric. Res. 81(2): 523-529.

El-Shafie, H. A. F. and J. R. Faleiro. 2017. Optimizing components of pheromone-baited trap for the management of red palm weevil, Rhynchophorus ferrugineus (Coleoptera: Curculionidae) in date palm agroecosystem. J. Plant Dis. Prot. 124(3): 279-287.

Estaban-Durán, J., J. L. Yela, F. Beitia-Crespo and A. Jiménez-Álvarez. 1998. Biología del curculiónido ferruginoso de las palmeras Rhynchophorus ferrugineus (Olivier) en laboratorio y campo: Ciclo en cautividad, peculiaridades biológicas en su zona de introducción en España y métodos biológicos de detacción y posible control (Coleoptera: Curculionidae: Rhynchophorinae). Boletín Sanidad Vegetal Plagas. 24: 737-748.

Faleiro, J. R. 2005. Pheromone Technology for the Management of Red Palm Weevil Rhynchophorus ferrugineus Olivier (Coleoptera: Rhynchophoridae) - A Key Pest of Coconut. Technical Bulletin No. 5. ICAR Research Complex for Goa (Indian Council for Agricultural Research-ICAR), Goa,p. 40.

Faleiro, J. R. 2006. A review of the issues and management of the red palm weevil Rhynchophorus ferrugineus (Coleoptera: Rhynchophoridae) in coconut and date palm during the last one hundred years. Int. J. Trop. Insect Sci. 26: 135-154.

Faleiro, J. R., V. A. Abraham and M. A. Al-Shuaibi. 1998. Role of pheromone trapping in the management of red palm weevil. Indian Coconut J. 29(5): 1-3.

Faleiro, J. R., V. A. Abraham, B. Nabil, M. A. Al-Shuaibi and T. P. Kumar. 2000. Field evaluation of red palm weevil, Rhynchophorus ferrugineus Oliv. pheromone (Ferrugineol) lures. Indian J. Entomol. 62(4): 427-433.

Faleiro, J. R., M. A. Al-Shuaibi, V. A. Abraham and T. P. Kumar. 1999. A technique to assess the longevity of the palm weevil pheromone (Ferrolure) under different conditions in Saudi Arabia. Agric. Sci. 4(1): 5-9.

Faleiro, J. R. and M. Chellapan. 1999. Attraction of red palm weevil Rhynchophorus ferrugineus Oliv. to ferrugineol based pheromone lures in coconut gardens. J. Trop. Agric. 37(1/2): 60-63.

Faleiro, J. R., M. A. El-Saad and A. H. Al-Abbad. 2011. Pheromone trap density to mass trap Rhynchophorus ferrugineus (Coleoptera: Curculionidae/Rhynchophoridae/Dryophoridae) in date plantations of Saudi Arabia. Int. J. Trop. Insect Sci. 31: 75-77.

Faleiro, J. R. and J. A. Kumar. 2008. A rapid decision sampling plan for implementing area-wide management of the red palm weevil, Rhynchophorus ferrugineus, in coconut plantations of Indian. J. Insect Sci. 8: 1536-2442.

Faleiro, J. R., J. A. Kumar and P. A. Rangnekar. 2002. Spatial distribution of red palm weevil Rhynchophorus ferrugineus Oliv. (Coleoptera: Curculionidae) in coconut plantations. Crop Prot. 21: 171-176.

Faleiro, J. R., P. A. Rangnekar and V. R. Satarkar. 2003. Age and fecundity of female red palm weevil Rhynchophorus ferrugineus (Olivier) (Coleoptera: Rhynchophoridae) captured by pheromone traps in coconut plantations of India. Crop Prot. 22: 999-1002.

Faleiro, J. R. and V. R. Satarkar. 2003a. Diurnal activity of red palm weevil, Rhynchophorus ferrugineus (Olivier) in coconut plantations of Goa. Insect Environ. 9(2): 63-64.

Faleiro, J. R. and V. R. Satarkar. 2003b. Ferrugineol based pheromone lures for trapping red palm weevil, Rhynchophorus ferrugineus Olivier (Coleoptera: Rhynchophoridae) in coconut plantations. Indian J. Plant Prot. 31: 84-87.

Faleiro, J. R. and V. R. Satarkar. 2005. Attraction of food baits for use in red palm weevil Rhynchophorus ferrugineus Olivier pheromone trap. Indian J. Plant Prot. 33(1): 23-25.

Ferry, M. and S. Gomez. 2002. The red palm weevil in the Mediterranean area. Palms. 46(4): 172-178.

Giblin-Davis, R. M., J. R. Faleiro, J. A. Jacas, J. E. Peña and P. S. P. Vidyasagar. 2013. Coleoptera: Biology and management of the red palm weevil, Rhynchophorus ferrugineus. In: J. E. Peña, (Ed.), Potential Invasive Pests of Agricultural Crop Species, CABI Wallingford, UK, pp. 1-34.

Gries, G., R. Gries, A. L. Perez, L. M. Gonzales, H. D. Pierce Jr., A. C. Oehlschlager, M. Rhainds, M. Zebeyou and B. Kouame. 1994. Ethyl propionate: synergistic kairomone for African palm weevil, Rhynchophorus phoenicis L. (Coleoptera: Curculionidae). J. Chem. Ecol. 20(4): 889-897.

Guarino, S., P. L. Bue, E. Peri and S. Colazza. 2011. Responses of Rhynchophorus ferrugineus adults to selected synthetic palm esters: Electroantennographic studies and trap catches in an urban environment. Pest Manag. Sci. 67: 77-81.

Gunawardena, N. E. and R. Gunatilake. 1993. Preliminary studies on a host attractant of the coconut pest, Rhynchophorus ferrugineus (Coleoptera: Curculionidae). J. Nat. Sci. Counc. Sri Lanka. 21: 93-101.

Hallett, R. H. 1996. Aggregation Pheromones of Coleopteran Pests of Palms. PhD Thesis. Simon Fraser University, Burnaby, Canada, p. 220.

Hallett, R. H., G. Gries, R. Gries, J. H. Borden, E. Czyzewska, A. C. Oehlschlager, H. D. Pierce Jr., N. P. D. Angerilli and A. Rauf. 1993a. Aggregation pheromones of two Asian palm weevils Rhynchophorus ferrugineus and $R$. vulneratus. Naturwissenschaften. 80: 328-331.

Hallett, R. H., A. C. Oehlschlager and J. H. Borden. 1999. Pheromone trapping protocols for the Asian palm weevil, Rhynchophorus ferrugineus (Coleoptera: Curculionidae). Int. J. Pest Manag. 45: 231-237.

Hallett, R. H., A. C. Oehlschlager, G. Gries, N. Angerilli, R. 
Al-Shareqi, M. Gassouma and J. Borden. 1993b. Field Testing of Aggregation Pheromone of Two Asian Palm Weevils. In: PORIM International Oil Palm Congress. pp. 661-668.

Hoddle, M. S., A. H. Al-Abbad, H. A. F. El-Shafie, J. R. Faleiro, A. A. Sallam and C. D. Hoddle. 2013. Assessing the impact of pheromone trapping, pesticide applications, and eradication of infested date palms for Rhynchophorus ferrugineus (Coleoptera: Curculionidae) management in Al Ghowaybah, Saudi Arabia. Crop Prot. 53: 152-160.

Hoddle, M. S. and C. D. Hoddle. 2011. Evaluation of three trapping strategies for red palm weevil, Rhynchophorus ferrugineus (Coleoptera: Curculionidae) in the Philippines. Pak. Entomol. 33(2): 77-80.

Hunsberger, A., R. Giblin-Davis and T. Weissling. 2000. Symptoms and population dynamics of Rhynchophorus cruentatus (Coleoptera: Curculionidae) in Canary Island date palms. Fla. Entomol. 83(3): 290-303.

Jaffe, K., P. Sanchez, H. Cerda, R. Hern`andez, N. Urdaneta, G. Guerra, R. Martinez and B. Miras. 1993. Chemical ecology of the palm weevil Rhynchophorus palmarum (L.) (Coleoptera: Curculionidae): Attraction to host plants and to a male-produced aggregation pheromone. J Chem. Ecol. 19: 1703-1720.

Jayanth, K. P., M. T. Mathew, G. B. Narabenchi and K. R. M. Bhanu. 2007. Impact of large scale mass trapping of red palm weevil Rhynchophorus ferrugineus Olivier in coconut plantations in Kerala using indigenously synthesized aggregation pheromone lures. Indian Coconut J. 38: 2-9.

Kaakeh, W. 2006. Toxicity of imidacloprid to developmental stages of Rhynchophorus ferrugineus (Curculionidae: Coleoptera): Laboratory and field tests. Crop Prot. 25: 432-439.

Kaakeh, W., F. El-Ezaby, M. M. A. Al-Nour and A. A. Khamis. 2001. Management of the Red Palm Weevil by a Pheromone/FoodBased Trapping System, $2^{\text {nd }}$ International Conference. On Date Palms, Al-Ain, UAE, March 25-27. pp. 325-343. Available from: http://www.pubhort.org/datepalm2/datepalm2-38.pdf. [Last accessed on 2017 May 15].

Kurian, C., V. A. Abraham and K. N. Ponnamma. 1984. Attractants - An Aid in Red Palm Weevil Management. In: Proc. PLACROSYM V, Dec. 15-18, 1982, Kasaragod, India. pp. 581-585.

Llacer, E., Ó. Dembilio and J. A. Jacas. 2010. Evaluation of the efficacy of an insecticidal paint based on chlorpyrifos and pyriproxyfen in a microencapsulated formulation against Rhynchophorus ferrugineus (Coleoptera: Curculionidae). J. Econ. Entomol. 103: 402-408.

Massoud, M. A., A. A. Sallam, J. R. Faleiro and S. Al-Abdan. 2012. Geographic information system-based study to ascertain the spatial and temporal spread of red palm weevil Rhynchophorus ferrugineus (Coleoptera: Curculionidae) in date plantations. Int. J. Trop. Insect Sci. 32(2): 108-115.

Muralidharan, C. M., U. R. Vaghasia and N. N. Sodagar. 1999. Population, food preference and trapping using aggregation pheromone (Ferrugineol) on red palm weevil (Rhynchophorus ferrugineus). Indian J. Agric. Sci. 69: 602-604.

Murphy, S. T. and B. R. Briscoe. 1999. The red palm weevil as an alien invasive: Biology and prospects for biological control as a component of IPM. Biol. Control. 20: 35-45.

Muthiah, C., C. Natarajan and C. P. R. Nair. 2005. Evaluation of pheromones in the management of red palm weevil in coconut. Indian Coconut J. 35(10): 15-17.

Nair, S. S., V. A. Abraham and C. P. R. Nair. 2000. Efficiency of different food baits in combination with pheromone lures in trapping adults of red weevil, Rhynchophorus ferrugineus Oliv. (Coleoptera: Curculionidae). Pestology. 24: 3-5.
Nirula, K. K. 1956. Investigations on the pests of coconut palm, Part-IV. Rhynchophorus ferrugineus. Indian Coconut J. 9: 229-247.

Oehlschlager, A. C. 1994. Use of Pheromone-Baited Traps in Control of Red Palm Weevil in the Kingdom of Saudi Arabia. Saudi Arabia: Consultancy Report Submitted to the Ministry of Agriculture. p. 17.

Oehlschlager, A. C. 1998. Trapping of the Date Palm Weevil. In: Proceedings of FAO Conference Workshop on Date Palm Weevil (Rhynchophorus ferrugineus) and its Control, Cairo, Egypt.

Oehlschlager,A. C. 2006. Mass Trapping as a Strategy for Management of Rhynchophorus Palm Weevils, I Jornada Internacional Sobre el Picudo Rojo de las Palmeras. pp. 143-180.

Oehlschlager, A. C. 2007. Optimizing trapping of palm weevils and beetles. Acta Hortic. 736: 347-368.

Oehlschlager, A. C. 2016. Palm weevil pheromones - Discovery and use. J. Chem. Ecol. 42(7): 617-630.

Oehlschlager, A. C., C. M. Chinchilla, G. Castillo and L. M. Gonzalez. 2002. Control of red ring disease by mass trapping of Rhynchophorus palmarum (Coleoptera: Curculionidae). Fla. Entomol. 85: 507-513.

Oehlschlager, A. C., C. M. Chinchilla, L. M. Gonzalez, L. F. Jiron, R. Mexon and B. Morgan. 1993. Development of a pheromonebased trapping system for Rhynchophorus palmarum (Coleoptera: Curculionidae). J. Econ. Entomol. 86(5): 1381-1392.

Peng, L. and Y. Hou. 2017. Red palm weevil Rhynchophorus ferrugineus (Olivier). In: Wan, F., M. Jiang and A. Zhan, (Eds.), Biological Invasions and its Management in China, Springer Nature, The Netherlands, pp. 245-256.

Poorjavad, N., S. H. Goldansaz and A. Avand-Faghih. 2009. Response of the red palm weevil Rhynchophorus ferrugineus to its aggregation pheromone under laboratory conditions. Bull. Insectol. 62(2): 257-260.

Rajamanickam, K., J. S. Kennedy and A. Christopher. 1995. Certain components of integrated management for red palm weevil, Rhynchophorus ferrugineus F. (Curculionidae: Coleoptera) on coconut. Mededelingen Faculteit Landbouwkundige Toegepaste Biologische Wetenschappen, Univ. Gent. 60(3a), 803-805.

Rajapakse, C. N. K., N. E. Gunawardena and K. F. G. Perera. 1998. Pheromone baited trap for the management of red palm weevil, Rhynchophorus ferrugineus F. (Coleoptera: Curculionidae) population in coconut plantations. COCOS. 13, 54-65.

Rochat, D. 2006. Trapping: Drawbacks and Prospects: Need for More Research. In: Proceedings of First International Workshop on Red Palm Weevil, Valencia, Spain, 28-29 November, 2005. Fundacion Agroalimed, Valencia, Spain, pp. 99-104.

Rochat, D., P. N. Meillour, J. R. Esteban-Duran, C. Malosse, B. Perthuis, J. P. Morin, and C. Descoins. 2000. Identification of pheromone synergistists in American palm weevil, Rhynchophorus palmarum, and attraction of related dynamis borassi. J. Chem. Ecol. 26: 155-187.

Roda, A., M. Kairo, T. Damian, F. Franken, K. Heidweiller, C. Johanns and R. Mankin. 2011. Red palm weevil (Rhynchophorus ferrugineus), an invasive pest recently found in the Caribbean that threatens the region. EPPO Bull. 41(2): 116-121.

Sivapragasam, A., A. Ngalim, B. Razali and M. S. Sukaime. 2010. Field trapping of the adult red stripe weevil, Rhynchophorus vulneratus (Panzer) with an aggregation pheromone in a coconut ecosystem. Planter. 86: 173-180.

Solaiman, R. H. A. and N. A. A. El-Latif. 2013. Seasonal flight activity and some attractants potency on the red palm weevil, Rhynchophorus ferrugineus using pheromones trap at Fayoum 
governorate, Egypt. J. Plant Prot. Path. Mansour. Univ. 4(11): 1011-1023.

Soroker, V., D. A. Blumberg, M. Haberman, S. Hamburger-Rishard, S. Reneh, L. Talebaev, L. Anshelevich, and A. R. Harari. 2005. Current status of red palm weevil infestation in date palm plantations in Israel. Phytoparasitica. 33(1): 97-106.

Soroker, V., A. Harari and J. R. Faleiro. 2015. The role of semiochemicals in date pest management. In: Wakil, W., J. R. Faleiro and T. Miller (Eds.), Sustainable Pest Management in Date Palm: Current Status and Emerging Challenges, Springer, Switzerland, p. 445.

Srichayet, P., P. Limsangouan and P. Kassamaporn. 2008. The Composition of Sugarcane Juice and Production of Granulated Sugar. Available from: http://www.panelamonitor.org/media/ docrepo/document/files/the-composition-of-sugarcane-juiceand-production-of-granulated-sugar.pdf. [Last accessed on 2017 May 28].

Vacas, S., M. Abad-Paya, J. Primo and V. Navarro-Llopis. 2014. Identification of pheromone synergists for Rhynchophorus ferrugineus trapping systems from Phoenix canariensis palm volatiles. J. Agric. Food Chem. 62: 6053-6064.

Vacas, S., O. Melita, A. Michaelakis, P. Milonas, R. Minuz, P. Riolo, M. K. Abbass, P. L. Bue, S. Colazza, E. Peri, V. Soroker, Y. Livne, J. Primo and V. Navarro-Llopis. 2017. Lures for red palm weevil trapping systems: aggregation pheromone and synthetic kairomone. Pest Manag. Sci. 73(1): 223-231.

Vacas, S., J. Primo and V. Navarro-Llopis. 2013. Advances in the use of trapping systems for Rhynchophorus ferrugineus (Coleoptera:
Curculionidae): Traps and attractants. J. Econ. Entomol. 106: 1739-1746.

Vidyasagar, P. S. P., S. A. Aldosari, E. M. Sultan, A. Al-Saihati and R. M. Khan. 2016. Efficiency of optimal pheromone trap density in management of red palm weevil, Rhynchophorus ferrugineus Olivier. Afr. J. Agric. Res. 11(12): 1071-1078.

Vidyasagar, P. S. P., A. A. Al-Saihati, O. E. Al-Mohanna, A. I. Subbei and A. M. Abdul-Mohsin. 2000a. Management of red palm weevil Rhynchophorus ferrugineus Olivier. A serious pest of date palm in Al-Qatif, Kingdom of Saudi Arabia. J. Plant. Crops. 28(10): 35-43.

Vidyasagar, P. S. P., M. Hagi, R. A. Abozuhairah, O. E. Al-Mohanna and A. A. Al-Saihati. 2000b. Impact of mass pheromone trapping on red palm weevil adult population and infestation level in date palm gardens of Saudi Arabia. Planter. 76(891): 347-355.

Vidyasagar, P. S. P. and K. Subaharan. 2000. Role of Behavior Modifying Chemicals in Management of Key Pests of Palms. In: Narsimhan, S., G. Suresh, S. D. Wesley (Eds.), Innovative Pest and Disease Management in Horticultural and Plantation Crops, SPIC Science Foundation, Chennai. The British Council, The British Deputy High Commission, Chennai, India,. pp. 121-126.

Weissling, T. J., R. M. Giblin-Davis, G. Gries, R. Gries, A. L. Perez and F. D. Pierce. 1994. Aggregation pheromone of the palmetto weevil, Rhynchophorus cruentatus (F.) (Coleoptera: Curculionidae). J. Chem. Ecol. 20: 505-515.

Zhang, C., S. A. Aldosari, P. S. P. Vidyasagar, P. Shukla and M. G. Nair. 2015. Determination of the variability of sugars in date fruit varieties. J. Plant. Crops. 43(1): 53-61. 